\title{
BMJ Open Cross-sectional study to measure household water insecurity and its health outcomes in urban Mexico
}

\author{
Wendy E Jepson (D) ," Justin Stoler (D) , ${ }^{2}$ Juha Baek (D) , ${ }^{3}$ Javier Morán Martínez, ${ }^{4}$ \\ Felipe Javier Uribe Salas, ${ }^{5}$ Genny Carrillo ${ }^{6}$
}

To cite: Jepson WE, Stoler J, Baek J, et al. Crosssectional study to measure household water insecurity and its health outcomes in urban Mexico. BMJ Open 2021;11:e040825. doi:10.1136/ bmjopen-2020-040825

- Prepublication history and additional materials for this paper is available online. To view these files, please visit the journal online (http://dx.doi. org/10.1136/bmjopen-2020040825).

Received 22 May 2020

Revised 24 January 2021

Accepted 10 February 2021

Check for updates

(C) Author(s) (or their employer(s)) 2021. Re-use permitted under CC BY-NC. No commercial re-use. See rights and permissions. Published by BMJ.

${ }^{1}$ Geography, Texas A\&M University, College Station, Texas, USA

${ }^{2}$ Geography, University of Miami, Coral Gables, Florida, USA

${ }^{3}$ Center for Outcomes Research, Houston Methodist, Houston,

Texas, USA

${ }^{4}$ Universidad Autónoma de Coahuila Facultad de Medicina Unidad Torreón, Torreón, Mexico ${ }^{5}$ El Colegio de la Frontera,

Piedras Negras, Mexico

${ }^{6}$ Environmental and

Occupational Health, Texas

A\&M University, College Station, Texas, USA

Correspondence to

Dr Wendy E Jepson;

wjepson@tamu.edu

\section{ABSTRACT}

Objective To assess the links between structural and household determinants of household water insecurity and test three water insecurity measures against self-reported diarrhoea, dengue fever and perceived stress in the middle-income and low-income urban areas of Torreón, Mexico.

Design Cross-sectional household survey conducted in two waves (rainy and dry seasons).

Participants 500 households selected via multistage cluster sample in selected communities. Socioeconomic status determined the selection of participant neighbourhoods; five were identified in low socioeconomic status neighbourhoods and five in low-medium socioeconomic status neighbourhoods. We examine how the context of urban water provision is related to a new cross-culturally valid Household Water Insecurity Experiences (HWISE) Scale.

Primary outcome measures The HWISE Scale, selfreported diarrhoea, dengue fever and the Perceived Stress Scale.

Results Water system intermittency (adjusted OR (AOR) $3.96,95 \% \mathrm{Cl} 2.40$ to $6.54, \mathrm{p}<0.001$ ), unpredictability (AOR $2.24,95 \% \mathrm{Cl} 1.34$ to $3.74, \mathrm{p}=0.002$ ) and the dry season (AOR 3.47, 95\% Cl 2.18 to 5.52, $p<0.001$ ) were structural correlates of the HWISE Scale. This study also found that the HWISE Scale was associated with two health outcomes, self-reported diarrhoea (AOR 1.09, 95\% Cl 1.03 to $1.15, p=0.002)$ and perceived stress $(\beta=0.28, S E=0.07$, $t=4.30, p<0.001$ ), but not self-reported dengue fever (AOR $1.02,95 \% \mathrm{Cl} 0.98$ to 1.06). A 3-item hygiene subscore and a 3-item water worry subscore were also both positively associated with self-reported diarrhoea and perceived stress.

Conclusion Short-form screeners of water insecurity may be useful for assessing certain health risks by lay survey workers in settings with limited healthcare resources, particularly in lieu of more expensive microbiological tests that require specialised training and facilities.

\section{INTRODUCTION}

Household water insecurity is more than unsafe water access: it is the interacting, copresent and cumulative lived experiences of precarious water and hydrosocial relations in the household. ${ }^{1-4}$ While household water insecurity has been an emergent concept with

\section{Strengths and limitations of this study}

This study employed the novel 12-item Household Water Insecurity Experiences Scale to determine the association between water insecurity experiences and health outcomes (self-reported diarrhoea, dengue, perceived stress).

- They study fits an ordinal logistic regression model to investigate the factors that predict household water insecurity.

- The study fits multiple logistic regression models and an ordinary least squares model to examine the associations between three water insecurity measures and health outcomes.

- This study does not determine the role of objective water quality measurements on health outcomes.

- The study does not examine intrahousehold water insecurity.

various, although related, definitions, ${ }^{5}$ recent research has offered household water insecurity as a novel way to consider the complex relationship among water insecurity, human biology and health. ${ }^{6-15}$

Critical advances seek to identify the pathways through which various experiences of household water insecurity, especially those conditions shaped by social inequality and vulnerability, contribute to adverse health effects and impede human well-being. Global health research in biocultural anthropology, for example, has made considerable advances in delineating the pathways and processes between water insecurity and mental or psychosocial distress. ${ }^{16-22}$ Groundbreaking work by Wutich and Ragsdale mapped out the relationship between household water insecurity, as measured by an empirically determined experiential scale, and emotional distress in periurban Bolivia. ${ }^{23}$ Studies of psychosocial distress and water insecurity have also revealed gendered differences. ${ }^{24} 25$ Subsequent case studies related to maternal and child health further refined our scientific understanding of the relationship between water insecurity and 
emotional distress. ${ }^{626}$ Sanitation, while beyond the scope of this study, has also been associated with increased gendered psychosocial distress. ${ }^{27-30}$ Water scarcity and restriction also effect body homoeostasis, highlighting the links between maternal water intake patterns or early life water restrictions and human health states and hydration behaviours. ${ }^{13}$ Most recently, Brewis et al observed a positive relationship between household water insecurity and women's high blood pressure, expanding our understanding of water insecurity's biocultural effects. ${ }^{31}$

The complex conditions of water insecurity-diverse water delivery mechanisms, variable service quality, local variability in water storage practices, different socioeconomic structures and community dynamics, and vector control practices-all bear on the transmission of waterborne disease. The many pathways between lack of access to clean water and disease are well documented. ${ }^{32} \mathrm{We}$ also know unsafe sanitation practices and lack of environmental hygiene lead to spread of infections. ${ }^{33}$ For example, breeding sites of Aedes aegypti are closely related to macroecological and microecological factors that are determined by human behaviours-individual, collective and institutional-and their related social, economic and political contexts. ${ }^{34}{ }^{35}$ Yet, few studies to date have empirically linked explicit metrics of household water insecurity experiences to waterborne or water-vector diseases. One study demonstrated that high water insecurity in lowland rural areas of the Bolivian Amazon was associated with significantly higher odds of diarrhoea for adults, suggesting that flooding events may exacerbate existing vulnerabilities because of displacement and deteriorated water quality. ${ }^{9}$ But the current study was conducted in an urban environment, and thus findings may not be generalisable to rural areas where the conditions of water insecurity manifest differently.

This study contributes to the growing body of empirical research that examines key relationships between correlates of household water insecurity, and between household water insecurity and health outcomes. We use the city of Torreónto explore how the context of urban water provision is related to a new cross-culturally valid Household Water Insecurity Experiences (HWISE) Scale. ${ }^{36}$ We then examined this metric's performance as a correlate of health outcomes by assessing the relationships between three versions of the HWISE metric (the 12-item HWISE Scale, a 3-item hygiene subscore and a 3-item water worry subscore) and self-reported diarrhoea, dengue and perceived stress. Our findings offer important insights about the pathways between household water insecurity and health, as well as the potential utility and limits of the HWISE Scale and its subcomponent constructs as a proxy for common health outcomes.

\section{METHODS}

\section{Study region}

The cross-sectional study lasted oneyear, and it was conducted in the city of Torreón, Coahuila, which is located in the Laguna region of northern Mexico. The city has the largest population size among regional municipalities, with 679288 inhabitants. ${ }^{37}$ National statistics report that the urban households are mostly connected to public services: $96.3 \%$ connect to a community water system, $99.2 \%$ have sanitation access and $99.8 \%$ have electricity. Yet, as with many urban areas in middle-income countries, Torreón reportedly faces high levels of water contamination in the public system. ${ }^{38-40}$ In this case, arsenic concentration in the public water supply is above the current WHO drinking water standards. ${ }^{41}$ Therefore, safe water availability has become a sensitive regional health concern, with water scarcity emerging as a salient part of everyday social, economic and political discourses.

\section{Household survey}

The survey, administered to 500 households, began with modules that solicited basic socioeconomic and demographic characteristics, and self-reported hygiene and sanitation, diarrhoea illness and dengue based on WHO modules. ${ }^{42}{ }^{43}$ Interviewees were asked if they or someone in their household had diarrhoea and dengue in the past 4 weeks. In addition, the survey included the HWISE Scale and Perceived Stress Scale (PSS-14). Study size was based on the HWISE Scale protocol.

The 12-item HWISE Scale was derived from the 29-item HWISE module (version 2), in which each item elicited information using a 4-week recall period and using five a priori frequency categories: never, rarely, sometimes, often and always. ${ }^{44}$ In the HWISE Scale, which probes experiential dimensions of water insecurity (table 1), the two frequency categories of 'often' and 'always' were collapsed into one category, and the scores ranged from 0 to $36 .{ }^{36}$

The PSS is a reliable and valid screening instrument for measuring perceived stress. ${ }^{45}{ }^{46}$ We applied the 14-item European Spanish version PSS, which demonstrates adequate reliability and internal consistency (Cronbach's $\alpha=0.81$ ) to confirm that the psychometric properties of the scale for evaluating perceived stress are adequate. ${ }^{478}$ Scores ranged from 0 to 56 with higher values indicating greater perceived stress.

\section{Data collection and sample frame}

Our household survey was conducted in two waves (rainy and dry seasons), and 250 households were selected via multistage cluster sample. We used census data to stratify neighbourhoods based on socioeconomic status. Because the prevalence of household water insecurity is frequently correlated with water accessibility, affordability and poor infrastructure, characteristics that are more common in lower income communities, we used census classifications to select five low and five low-medium socioeconomic status neighbourhoods. ${ }^{37}$ To minimise spatial autocorrelation, we used Google Earth images to identify the structure of each neighbourhood and divide it into sampling quadrants. Within each quadrant, enumerators randomly surveyed 20-25 households. The two survey waves took 
Table 1 Item composition of HWISE Scale, hygiene subscore and water worry subscore

\begin{tabular}{|c|c|c|c|c|}
\hline Label & Survey item & $\begin{array}{l}\text { HWISE } \\
\text { Scale }\end{array}$ & $\begin{array}{l}\text { Hygiene } \\
\text { subscore }\end{array}$ & $\begin{array}{l}\text { Water worry } \\
\text { subscore }\end{array}$ \\
\hline Clothes & $\begin{array}{l}\text { In the last } 4 \text { weeks, how frequently has there not been enough water in the } \\
\text { household to wash clothes? }\end{array}$ & $x$ & & \\
\hline Drink & $\begin{array}{l}\text { In the last } 4 \text { weeks, how frequently has there not been as much water to drink as you } \\
\text { would like for you or anyone in your household? }\end{array}$ & $x$ & & \\
\hline Food & $\begin{array}{l}\text { In the last } 4 \text { weeks, how frequently have you or anyone in your household had to } \\
\text { change what was being eaten because there were problems with water (eg, for } \\
\text { washing foods, cooking, and so on)? }\end{array}$ & $x$ & & \\
\hline Interruption & $\begin{array}{l}\text { In the last } 4 \text { weeks, how frequently has your household water supply from your } \\
\text { main water source been interrupted or limited (eg, water pressure, less water than } \\
\text { expected)? }\end{array}$ & $x$ & & \\
\hline No water & $\begin{array}{l}\text { In the last } 4 \text { weeks, how frequently has there been no useable or drinkable water } \\
\text { whatsoever in your household? }\end{array}$ & $x$ & & \\
\hline Sleep & $\begin{array}{l}\text { In the last } 4 \text { weeks, how frequently have you or anyone in your household gone to } \\
\text { sleep thirsty because there wasn't any water to drink? }\end{array}$ & $x$ & & \\
\hline Angry & $\begin{array}{l}\text { In the last } 4 \text { weeks, how frequently did you or anyone in your household feel angry } \\
\text { about your water situation? }\end{array}$ & $x$ & & $x$ \\
\hline Shame & $\begin{array}{l}\text { In the last } 4 \text { weeks, how frequently have problems with water caused you or anyone } \\
\text { in your household to feel ashamed/excluded/stigmatised? }\end{array}$ & $x$ & & $x$ \\
\hline Worry & $\begin{array}{l}\text { In the last } 4 \text { weeks, how frequently did you or anyone in your household worry you } \\
\text { would not have enough water for all of your household needs? }\end{array}$ & $x$ & & $x$ \\
\hline Body & $\begin{array}{l}\text { In the last } 4 \text { weeks, how frequently have you or anyone in your household had to go } \\
\text { without washing their body because of problems with water (eg, not enough water, } \\
\text { dirty, unsafe)? }\end{array}$ & $x$ & $x$ & \\
\hline
\end{tabular}

Items classified as never (0 times), rarely (1-2 times), sometimes (3 times) and often/always (11 times or more); the score ranges are 0-36 for HWISE Scale, and 0-9 for hygiene subscore and water worry subscore.

HWISE, Household Water Insecurity Experiences.

place in April 2018 (dry season) and September 2018 (rainy season).

\section{Patient and public involvement}

This research was done without participant or public involvement.

\section{DATA ANALYSIS}

\section{Household water and sanitation}

We computed summary and descriptive statistics for key household water and sanitation characteristics. We aggregated data on household water sources to replicate three categories used by the WHOJoint Monitoring Programme (JMP): piped water, other improved water (protected borehole) and unimproved water (water vendor, tanker truck, bottled water, bagged or sachet water, or other). We categorised various forms of vended or packaged water into the 'unimproved category' because these sources could not be verified as safely managed.

\section{Household water insecurity}

We calculated the 12-item HWISE Scale for each household. We then constructed a categorical variable, similar to Rosinger ${ }^{9}$ and Jepson and Vandewalle, ${ }^{49}$ using a cutpoint of 12 which reflects a household experiencing at least half of the 12 HWISE Scale items 'sometimes' in the past 4 weeks. ${ }^{36}$ Using this cut-point as an anchor, we defined the five categories using the HWISE Scale score: (1) marginal insecurity (0-3); (2) low water insecurity (4-11); (3) moderate water insecurity (12-20); (4) high water insecurity (21-29); (5) extreme water insecurity (30-36). We created ordered categories using the scale score because we wanted to identify which factors were associated with substantive changes in household water 
insecurity experiences, operationalised here as a change in category, rather than assess correlates of a less meaningful one-point change in the HWISE Scale score.

\section{Correlates of household water insecurity}

To assess the correlates of the five-category HWISE measure, we fitted an ordinal logistic regression (OLR) model to investigate the factors that predict household water insecurity. This model estimates the cumulative probability of being in a higher HWISE category, that is, exhibiting a higher degree of water insecurity. We report adjusted ORs and 95\% CIs for higher water insecurity categories relative to remaining in the same category, using a significance threshold of $\alpha=0.05$. Table 2 summarises our independent measures, which include factors known to contribute to, or mitigate, water insecurity: gender of household head, monthly income (in US\$), household size (number of household members) and type of housing. We also included proxy measures for several constituents of complex water provisioning systems that shape or reflect household water decisions: intermittency, predictability, seasonality, satisfaction with current water situation, household water expenditures as a percentage of monthly income, total number of water sources, safe water storage, primary drinking water source and primary non-drinking water source. Prior to model fitting, we computed variance inflation factors (VIF) for our set of candidate independent variables to assess potential multicollinearity, and used a conservative VIF threshold of 4 for removing items.

\section{Household water insecurity and health outcomes}

We fitted multiple logistic regression models to examine the associations between three water insecurity measures and the two binary health outcomes, self-reported diarrhoea and dengue, after adjusting for covariates. We fitted multiple ordinary least squares models to examine the association between the water insecurity measures and the PSS score. The three water insecurity measures were the exposures of interest: the 12-item HWISE Scale (range $0-36)$, a 3-item hygiene subscore (0-9) computed as the sum of the three hygiene-related questions and a 3-item water worry subscore (0-9) computed as the sum of three psychosocial distress questions (table 1). Each model estimates the probability of a household reporting a given health outcome, using just one water insecurity measure per model. We again conducted multicollinearity assessments before fitting these models.

\section{RESULTS}

\section{Descriptive statistics}

Frequency characteristics and univariate statistics of study households $(n=498)$ are presented in table 2. Data from two households from the original sample of 500 were incomplete, and therefore, we removed them from the analysis. About two-thirds of household heads were male $(67.5 \%)$, and the households had 3.7 members
Table 2 Descriptive characteristics of households $(n=498)$

\begin{tabular}{ll} 
Characteristic & Mean \pm SD or \% \\
\hline Female household head & $32.50 \%$ \\
$\begin{array}{l}\text { Household size (number of household } \\
\text { members) }\end{array}$ & $3.7 \pm 1.8$ \\
$\begin{array}{l}\text { Number of children in household (16 years } \\
\text { and younger) }\end{array}$ & $1.2 \pm 1.3$ \\
\hline
\end{tabular}

Number of adults in household (17 and older) $2.5 \pm 1.1$

Type of housing

Owned 83.10\%

Rented $\quad 15.30 \%$

Other $1.60 \%$

Monthly household income (US\$) $335.3 \pm 288.2$

Monthly water expenditures (US\$, as \% of $3.5 \pm 7.2$ monthly income)

\begin{tabular}{|c|c|}
\hline Intermittent water supply & $49.60 \%$ \\
\hline Unpredictable water supply & $62.80 \%$ \\
\hline \multicolumn{2}{|c|}{ Satisfaction with current water situation } \\
\hline Completely satisfied & $23.90 \%$ \\
\hline Often satisfied & $16.30 \%$ \\
\hline Sometimes satisfied & $29.70 \%$ \\
\hline Rarely satisfied & $12.00 \%$ \\
\hline Not at all satisfied & $18.10 \%$ \\
\hline Total number of water sources & $2.1 \pm 0.7$ \\
\hline \multicolumn{2}{|l|}{ Primary drinking water source } \\
\hline Piped or other improved & $29.50 \%$ \\
\hline Unimproved & $70.50 \%$ \\
\hline \multicolumn{2}{|l|}{ Primary non-drinking water source } \\
\hline Piped or other improved & $96.60 \%$ \\
\hline Unimproved & $3.40 \%$ \\
\hline \multicolumn{2}{|l|}{ Secondary drinking water source } \\
\hline Piped or other improved & $56.60 \%$ \\
\hline Unimproved & $45.40 \%$ \\
\hline \multicolumn{2}{|l|}{ Secondary non-drinking water source } \\
\hline Piped or other improved & $76.60 \%$ \\
\hline Unimproved & $23.40 \%$ \\
\hline \multicolumn{2}{|l|}{ Water storage } \\
\hline Safe storage & $51.20 \%$ \\
\hline Unsafe storage & $45.60 \%$ \\
\hline No storage & $3.20 \%$ \\
\hline Interviewed in dry season & $49.80 \%$ \\
\hline Interviewed in wet season & $50.20 \%$ \\
\hline \multicolumn{2}{|c|}{ Household water insecurity measures } \\
\hline HWISE Scale score (range 0-36) & $7.6 \pm 7.9$ \\
\hline Hygiene subscore (0-9) & $0.97 \pm 1.75$ \\
\hline Water worry subscore (0-9) & $2.45 \pm 2.44$ \\
\hline \multicolumn{2}{|c|}{ Household water insecurity (five categories) } \\
\hline No water insecurity $(0-3)$ & $43.00 \%$ \\
\hline Marginal water insecurity (4-11) & $29.90 \%$ \\
\hline
\end{tabular}

Continued 


\begin{tabular}{ll}
\hline Table 2 Continued & \\
\hline Characteristic & Mean \pm SD or \% \\
\hline \multicolumn{1}{c}{ Moderate water insecurity (12-20) } & $18.30 \%$ \\
\hline Elevated water insecurity (21-29) & $7.60 \%$ \\
\hline Extreme water insecurity (30-36) & $1.20 \%$ \\
Health outcomes & $9.20 \%$ \\
Self-reported diarrhoea & $18.50 \%$ \\
Self-reported dengue fever & $19.72 \pm 8.98$ \\
\hline Perceived Stress Scale (PSS) score &
\end{tabular}

HWISE, Household Water Insecurity Experiences.

on average. Most of the participants owned their house $(83.1 \%)$ and the mean monthly income was about $\$ 335$. Approximately half of the participants $(49.6 \%)$ reported their water availability is intermittent and $62.8 \%$ of them had unpredictable water availability. About $70 \%$ of households were satisfied with their current water situation (completely, often or sometimes) and an average of 3.4\% of monthly income was spent on water. The participants relied on an average of two water sources, and most of the households had unimproved water for their primary drinking water $(70.5 \%)$ and primary piped water for their non-drinking water $(96.6 \%)$. Over half of participants $(51.2 \%)$ used safe water storage. The mean HWISE Scale score and hygiene subscore were 7.6 and 0.97 , respectively. Forty-three per cent of participants reported marginal water insecurity in the households while $30 \%$ and $18.3 \%$ experienced low and moderate water insecurity, respectively. $8.8 \%$ of households experienced high and extreme water insecurity. $9.2 \%$ and $18.5 \%$ of the households reported diarrhoea (gastrointestinal disease) and dengue, respectively. The mean PSS score was 19.72. Bivariate relationships between household characteristics and self-reported diarrhoea, dengue fever and psychosocial stress are presented in online supplemental material. We examined these relationships as an additional way of assessing potential multicollinearity and to guide multivariable model building.

\section{Correlates of water insecurity}

Table 3 presents the OLR model of the categorical HWISE Scale. Three independent measures were significantly associated with being in a higher household water insecurity category: intermittent water supply (IWS) (OR 3.96, $95 \%$ CI 2.40 to $6.54, \mathrm{p}<0.001$ ), unpredictable water (OR 2.24, $95 \%$ CI 1.34 to $3.74, \mathrm{p}=0.002)$ and the dry season (OR $3.47,95 \%$ CI 2.18 to 5.52 , p $<0.001$ ). Four independent measures were significantly associated with being in a lower household water insecurity category: monthly income (OR $0.998,95 \%$ CI 0.996 to 0.999 , $\mathrm{p}<0.001$ ), satisfaction with current water situation (OR $0.48,95 \%$ CI 0.40 to $0.57, \mathrm{p}<0.001$ ), water expenditures ( $\%$ of monthly income spent on water) (OR $0.96,95 \%$ CI 0.93 to 0.99 , $\mathrm{p}=0.004)$ and using an unimproved primary drinking water source (OR $0.63,95 \%$ CI 0.41 to $0.97, \mathrm{p}=0.036)$.
Table 3 Ordinal logistic regression model of the categorical Household Water Insecurity Experiences (HWISE) Scale

\begin{tabular}{|c|c|}
\hline Characteristic & OR (95\% Cl) \\
\hline $\begin{array}{l}\text { Female household head (Ref: } \\
\text { Male) }\end{array}$ & 0.947 (0.628 to 1.429$)$ \\
\hline Monthly income (US\$) & $0.998(0.996 \text { to } 0.999)^{\star \star *}$ \\
\hline Monthly water expenditures (US\$) & $0.957(0.929 \text { to } 0.986)^{\star \star}$ \\
\hline Dry season (Ref: Wet season) & $3.467(2.178 \text { to } 5.520)^{\star \star \star}$ \\
\hline Number of household members & $1.060(0.955$ to 1.175$)$ \\
\hline Intermittent water supply & $3.960(2.396 \text { to } 6.544)^{\star \star \star}$ \\
\hline Unpredictable water supply & $2.239(1.341 \text { to } 3.738)^{\star *}$ \\
\hline Satisfaction with water situation & $0.481(0.403 \text { to } 0.573)^{\star \star \star}$ \\
\hline \multicolumn{2}{|l|}{ Housing type (Ref: Owned) } \\
\hline Rented & 0.902 (0.531 to 1.533$)$ \\
\hline Other & 4.255 (0.919 to 19.696$)$ \\
\hline \multicolumn{2}{|l|}{ Water storage (Ref: No storage) } \\
\hline Unsafe storage & $1.813(0.440$ to 7.471$)$ \\
\hline Safe storage & $1.241(0.310$ to 4.967$)$ \\
\hline $\begin{array}{l}\text { Unimproved primary drinking } \\
\text { water source (Ref: Piped or other } \\
\text { improved) }\end{array}$ & $0.628(0.407 \text { to } 0.970)^{*}$ \\
\hline
\end{tabular}

Unimproved primary non-drinking 1.281 (0.459 to 3.570)

water source (Ref: Piped or other improved)

Unimproved secondary drinking
water source (Ref: Piped or other
improved)

${ }^{*} \mathrm{P}<0.05 ;{ }^{* *} \mathrm{p}<0.01 ;{ }^{* * *} \mathrm{p}<0.001$.

\section{Health outcomes}

Tables 4-6 present the results of the multiple logistic regression models of the associations between each of the three household water insecurity measures (HWISE Scale, hygiene subscore and water worry subscore) as exposure of interest, and three self-reported health outcomes, controlling for household characteristics. We use the HWISE Scale score as the independent variable in this analysis, rather than the categorical version, so that we can compare the regression coefficient with the corresponding coefficients from the HWISE subscore analyses using the same units (ie, a 1-unit change in any scale).

\section{Self-reported diarrhoea}

The 12-item HWISE Scale score (model 1; OR 1.09, 95\% CI 1.03 to $1.15, \mathrm{p}=0.002$ ), the hygiene subscore (model 2; OR $1.38,95 \%$ CI 1.14 to $1.66, \mathrm{p}=0.001$ ) and the water worry subscore (model 3; OR 1.33, 95\% CI 1.09 to 1.63 , $\mathrm{p}=0.005$ ) were all significantly and positively associated with self-reported diarrhoea (table 4, models 1-3). Monthly water expenditures and use of an unimproved primary 
Table 4 Multiple regression models of self-reported diarrhoea using three household water insecurity measures

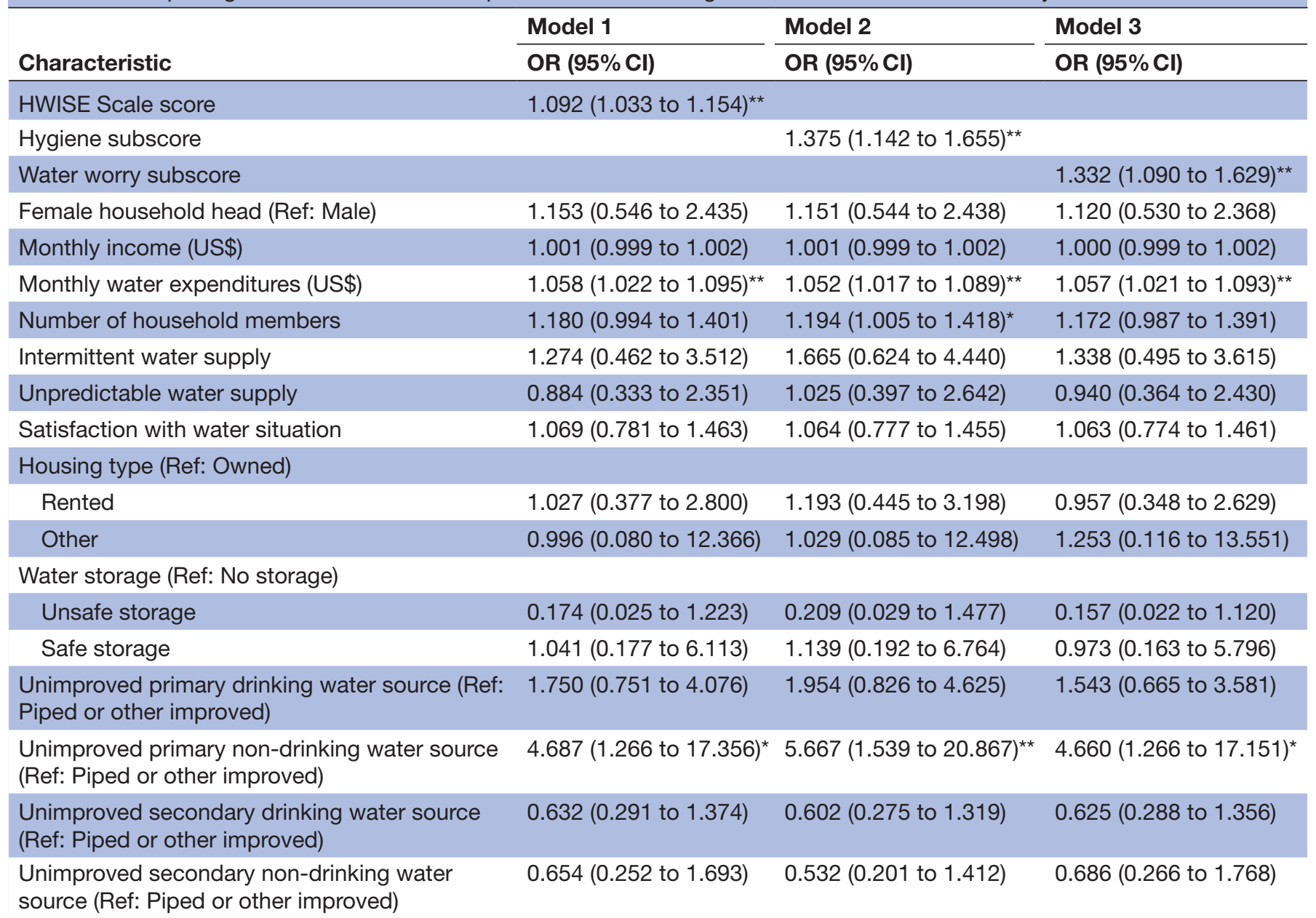

${ }^{*} \mathrm{P}<0.05 ;{ }^{* *} \mathrm{p}<0.01$

HWISE, Household Water Insecurity Experiences.

non-drinking water source were also significantly and positively associated with diarrhoea, regardless of the water insecurity metric. The effect size was particularly strong for use of an unimproved primary non-drinking water source (OR ranging from 4.66 to 5.66), suggesting that these sources may present some opportunity for cross-contamination in the household, or perhaps are occasionally used for drinking, in either case increasing risk of diarrhoea.

\section{Self-reported dengue fever}

The HWISE Scale score, hygiene score and water worry score were not significantly associated with dengue (table 5, models 4-6). Unpredictable water supply (OR ranging from 3.07 to 3.38 ) was the only variable consistently associated with self-reported dengue. This relationship may be a proxy for a particular aspect of water storage, given that our water storage measure was nonsignificant in all three models of self-reported dengue.

Self-reported perceived stress

The HWISE score, water hygiene subscore and water worry score were positively and significantly associated with selfreported perceived stress (table 6, models 7-9). There was variation in effect size of the association with PSS between the HWISE score $(\beta=0.28, t=4.30, p<0.001)$, hygiene subscore $(\beta=0.56, t=2.21, \mathrm{p}=0.028)$ and water worry score $(\beta=1.18, t=5.54, p<0.001)$, with the water worry subscore having the strongest effect on PSS. Female-headed households, being surveyed during the dry season and using an unimproved secondary drinking water source were significantly and positively associated with PSS regardless of which water insecurity metric was in a given model. Monthly income, using an unimproved primary drinking water source and using an unimproved secondary nondrinking water source were significantly and negatively associated with PSS. Model 8 also indicated water predictability and 'other' housing arrangements (ie, neither rented nor owned) were significantly and positively associated with PSS. As a sensitivity check, we fitted identical multivariable ordinal regression models of a categorical (quantile-based) PSS outcome measure; most relationships were the same to those presented in table 6, except that the relationship between the hygiene subscore and PSS was no longer significant (see online supplemental materials). 
Table 5 Multiple regression models of self-reported dengue fever using three household water insecurity measures

\begin{tabular}{|c|c|c|c|}
\hline \multirow[b]{2}{*}{ Characteristic } & Model 4 & Model 5 & Model 6 \\
\hline & OR (95\% Cl) & OR $(95 \% \mathrm{Cl})$ & OR (95\% Cl) \\
\hline HWISE Scale score & $1.020(0.977$ to 1.064$)$ & & \\
\hline Water worry subscore & & & $1.039(0.901$ to 1.198$)$ \\
\hline Female household head (Ref: Male) & $0.782(0.454$ to 1.347$)$ & $0.782(0.454$ to 1.347$)$ & 0.805 (0.466 to 1.389$)$ \\
\hline Dry season (Ref: Wet season) & 1.543 (0.849 to 2.804$)$ & $1.564(0.868$ to 2.820$)$ & 1.615 (0.891 to 2.929$)$ \\
\hline Number of household members & 1.098 (0.959 to 1.257$)$ & $1.099(0.960$ to 1.258$)$ & 1.087 (0.949 to 1.245$)$ \\
\hline Intermittent water supply & 0.588 (0.296 to 1.168$)$ & 0.627 (0.327 to 1.204$)$ & $0.584(0.293$ to 1.164$)$ \\
\hline Unpredictable water supply & $3.074(1.591 \text { to } 5.939)^{\star \star}$ & $3.114(1.615 \text { to } 6.005)^{\star \star}$ & $3.385(1.737 \text { to } 6.594)^{\star \star \star}$ \\
\hline Other & $0.396(0.044$ to 3.554$)$ & 0.404 (0.045 to 3.399$)$ & 0.426 (0.048 to 3.803$)$ \\
\hline \multicolumn{4}{|l|}{ Water storage (Ref: No storage) } \\
\hline Unsafe storage & $0.857(0.205$ to 3.351$)$ & $0.891(0.212$ to 3.740$)$ & $0.821(0.196$ to 3.445$)$ \\
\hline Safe storage & 0.828 (0.206 to 3.328$)$ & 0.843 (0.209 to 3.402$)$ & 0.811 (0.201 to 3.267$)$ \\
\hline $\begin{array}{l}\text { Unimproved primary drinking water source (Ref: } \\
\text { Piped or other improved) }\end{array}$ & $1.004(0.557$ to 1.808$)$ & $1.013(0.561$ to 1.831$)$ & $1.004(0.555$ to 1.813$)$ \\
\hline $\begin{array}{l}\text { Unimproved primary non-drinking water source } \\
\text { (Ref: Piped or other improved) }\end{array}$ & $1.112(0.336$ to 3.678$)$ & $1.145(0.347$ to 3.778$)$ & $1.108(0.333$ to 3.681$)$ \\
\hline $\begin{array}{l}\text { Unimproved secondary drinking water source (Ref: } \\
\text { Piped or other improved) }\end{array}$ & $1.298(0.775$ to 2.175$)$ & $1.289(0.769$ to 2.161$)$ & $1.258(0.748$ to 2.117$)$ \\
\hline
\end{tabular}

${ }^{\star *} \mathrm{p}<0.01 ;{ }^{* * *} \mathrm{p}<0.001$.

HWISE, Household Water Insecurity Experiences.

\section{DISCUSSION}

This study explored the links between household characteristics and household water insecurity, and tested three water insecurity measures against self-reported diarrhoea, dengue fever and perceived stress in the urban context of Torreón, Mexico. We found a set of seasonal and structural factors to be associated with higher household water insecurity, with IWS and seasonality exerting the strongest effects, and water insecurity declining for those at higher income levels. We also found that although the 12-item HWISE Scale was associated with self-reported diarrhoea and perceived stress, 3-item subscores for hygiene and water worry yielded much stronger associations with these outcomes, suggesting that construct-specific water insecurity scales may be effective screeners of certain health issues. The remainder of this section discusses each of the main findings in turn, and reflects on the utility and limits of the HWISE Scale.

\section{Correlates of household water insecurity}

The OLR model indicated that IWS had the strongest relationship with higher household water insecurity among all of the characteristics tested. IWS is an important characteristic of domestic water provision in low-income and middle-income countries across the globe. While access to piped water has increased over the past decade, water supplied through these networks may not provide continuous or reliable water. ${ }^{50}$ Causes of IWS are complex, ranging from systemic failures and disrepairs to governance practices and policies..$^{51-54}$ Negative outcomes of intermittency are unequal across the system. ${ }^{55}$ In some cases, IWS is a water management strategy during drought, or IWS is caused by system failure because of overexpansion. In Mexico, for example, $5.8 \%$ of water customers with a water supply experience discontinuous service during normal operation. ${ }^{56}$ Water pressure drops and water loss incidents increase during and immediately after the periods of IWS events, thus increasing water contamination risk through intrusion or backflow. ${ }^{57} 58$

We should not be surprised, then, that IWS increases the odds of household water insecurity. IWS, by default or by policy, impairs or compromises experiences of water service, water quality and water delivery. Behavioural 
Table 6 OLS models of self-reported perceived stress using three household water insecurity measures

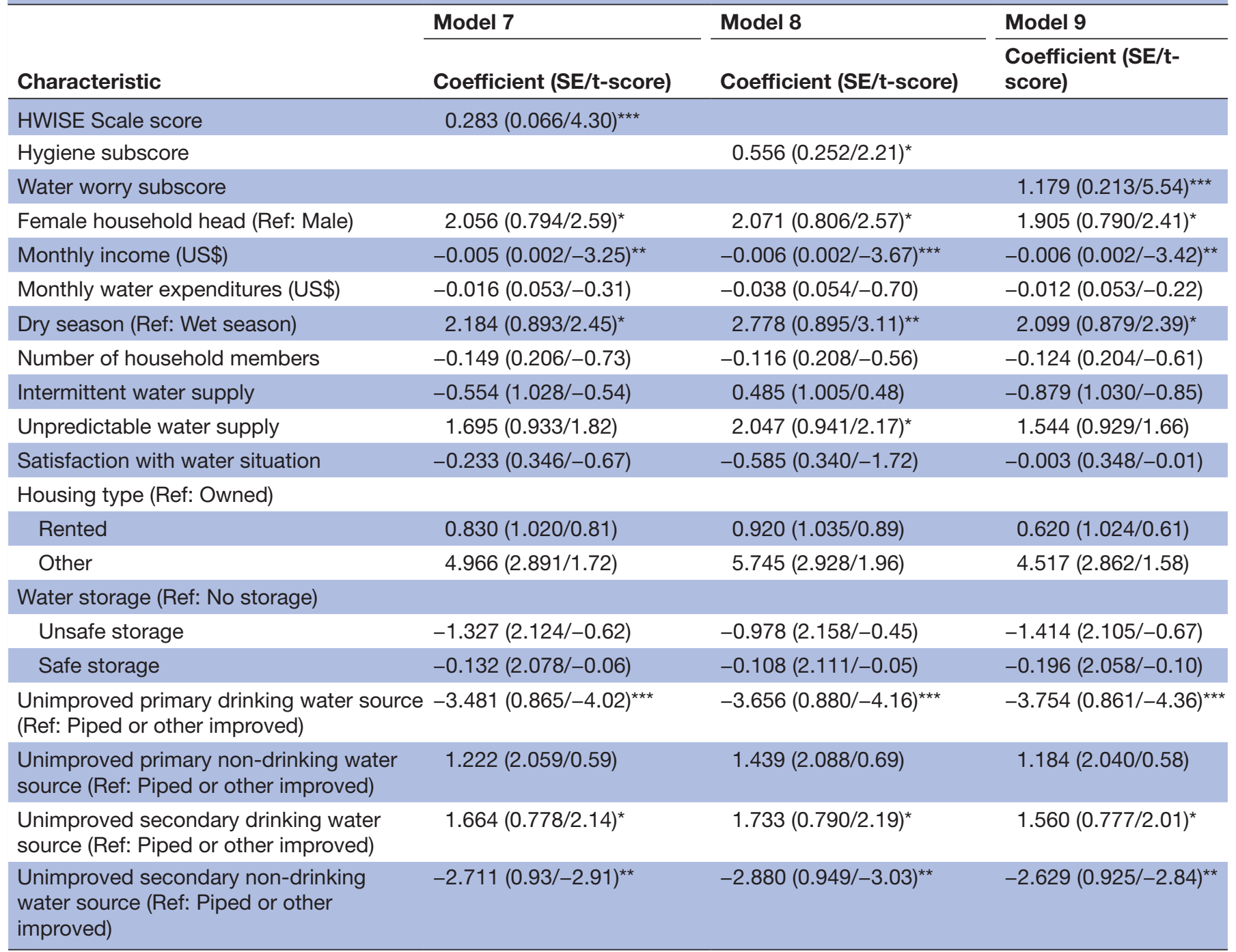

${ }^{*} \mathrm{P}<0.05 ;{ }^{* *} \mathrm{p}<0.01 ;{ }^{* * *} \mathrm{p}<0.001$.

HWISE, Household Water Insecurity Experiences; OLS, ordinary least squares.

responses to IWS include increased water storage, and that response, in turn, increases risk of water quality contamination, thereby undermining the efficacy of piped water for public health outcomes. The impact of IWS on water quantity also limits personal hygiene, clothes washing, and even requires people to change their daily plans to adapt to the water situation.

Unpredictability, that is, water service that does not supply a certain quantity of water on an expected timeline, has similar effects as IWS. Unpredictable water provision prevents household planning for disruptions, which also increases water worry and other disruptions to everyday life and further exacerbates water insecurity. ${ }^{59}$ Thus, we are not surprised that unpredictable water supply increased the odds for households to increase in water insecurity, as observed in other contexts. ${ }^{60-63}$

We did not anticipate a strong seasonal signal because $92.8 \%$ of the households had connections to a community water system, which is commonly presumed to mitigate seasonal variation. But our results indicated that the dry season positively correlates with household water insecurity. There are three possible explanations. Reliance on non-piped water for drinking may be highly variable during the dry season, although this explanation is contradicted by the finding that households with unimproved water as primary source of drinking water were $37 \%$ less likely to move in to a higher water insecurity category. A second explanation is that piped water system performance is highly variable across then seasons due to changes in supply. However, Torreón draws its urban water supply from groundwater sources. While the region experiences a perpetually dropping water table, the water source is protected from seasonal changes because urban wells use more energy to draw from deeper depths. ${ }^{40} \mathrm{~A}$ third, and most likely explanation, is that water supplies are unable to meet higher water demands during the dry season, and thus a range of water supply problems may 
increase, and thus odds of increasing water insecurity are greater.

We anticipated that income, satisfaction with water situation, water storage capacity and number of water sources would have decreased the likelihood of water insecurity. Households with higher monthly incomes were less likely to experience water insecurity; for every additional $\$ 100$ in monthly income, a household was $20 \%$ more likely to be in a lower HWISE Scale category. The relationship between satisfaction with one's water situation and lower water insecurity reflects how people are cognisant of water insecurity. Water storage and number of water sources were not significant, yet households that rely on unimproved primary sources of drinking water (eg, rainwater collection, water vendors, tanker trucks, bottled water, sachet water) were $37 \%$ less likely to increase water insecurity. The local context may explain this unanticipated result. Households regularly sought other drinking sources due to fears of arsenic contamination in the city's water supply. Purchasing water outside the piped network may offer residents a perceived safer drinking water option, and one that is more reliable even if more expensive. In addition, this result may also explain why Torreón households who spend a higher proportion of their income on water were more likely to have lower water insecurity, in contrast with the positive relationship between water expenditures and water insecurity observed globally. ${ }^{64}$

\section{Household water insecurity as proxy for health risk}

The 12-item HWISE Scale score was positively associated with self-reported diarrhoea and perceived stress. The relationship between household water insecurity experiences and diarrhoea presents a potential new indicator for drinking water quality problems, a characteristic that has traditionally been assessed by microbiological field tests with greater financial and time costs. ${ }^{65}$ The relationship between water insecurity and psychosocial health is consistent with results from recent studies and adds to a growing literature that recognises the dual mental and physical health burdens of water insecurity.

The hygiene subscore was also positively associated with self-reported diarrhoea with a much stronger signal than the full HWISE Scale (37\% vs 9\% more likely to report diarrhoea). Although this is consistent with the subscore ranges being one-fourth that of the HWISE Scale (0-9 vs $0-36)$, this suggests an important trade-off of the full HWISE Scale: in trying to unidimensionally represent the complicated construct of water insecurity, it is less useful for identifying specific health issues that may be a consequence of specific constructs of water insecurity, such as insufficient water quantity. We observed a similar effect with the water worry subscore, which yielded approximately four times the effect on diarrhoea and perceived stress than the HWISE Scale. The significant relationship between the water worry subscore and diarrhoea particularly underscores the intricate relationship between dimensions of water insecurity and human biology that have attracted recent attention. ${ }^{14}$ Although the true utility of the 3-item hygiene and water worry subscores requires reassessment in different contexts, these tools may be promising screeners for lay workers to rapidly assess risk of waterborne illness and water-related stress and anxiety through the simultaneous evaluation of household water insecurity.

None of the water insecurity metrics were associated with self-reported dengue fever. Unpredictability of water supply was the only household or water system characteristic that was positively associated with self-reported dengue fever. Adaptation to unpredictable water access often involves water storage, and unsafe storage is a risk factor for $A$. aegypti breeding and subsequent dengue transmission. Our storage variable, which characterised water storage as safe, unsafe or none, was not associated with dengue. Given the inherent bias of households selfreporting the nature of their water storage, we refitted the OLR model using a binary storage variable that indicated any form of storage versus none. The model results were virtually identical, so it is possible that unpredictability leads to a certain type of water storage (or other behaviour) and thus captures all the variation in selfreported dengue fever. Future studies of water insecurity and Aedes-transmitted diseases such as dengue should explore the interaction of unpredictability and water storage. This result also highlights the limitations of the HWISE Scale, the contents of which do not appear to be an appropriate proxy for dengue fever risk in this context, despite being associated with other health outcomes.

The primary and secondary drinking water source measures, which serve as proxies for JMP water access ladder categories, were unexpectedly not associated with self-reported diarrhoea or dengue. While water sources may influence water quality parameters, this result demonstrates how the experience of water insecurity may lead to household adaptation that consequently mitigates a particular health risk. Second, intermittency was not associated with any health outcome, despite how intermittency places water quality at greater risk. We suggest that considerable reliance on non-piped water may buffer the negative impacts of intermittency in Torreón.

\section{Household water insecurity metrics}

Our findings offer important insights about the possible correlates of household water insecurity and the relationship between different constructs of household water insecurity and common health outcomes. First, primary drinking water source, which is frequently used as a proxy of water quality and, consequently, waterborne disease risk, was neither associated with household water insecurity nor correlated with diarrhoea or dengue.

Instead, our study indicates that experiences of household water insecurity influence how people access and store water. In particular, water service's temporal dimensions such as water intermittency and predictability were associated with higher water insecurity scores. ${ }^{62}$ This is important because it further demonstrates that the water 
insecurity is about the kind of water and about the variegated and relational flow of water between people and water systems that shape the experience of water insecurity. ${ }^{4}$ Intermittency and unpredictability are often tied to infrastructure, as they are indicators of water governance performance. Our results highlighting how intermittency and unpredictability are related to water insecurity add to the emerging evidence that water governance influences household water insecurity. ${ }^{66}$

The relationship between seasonality and health outcomes is less clear, but our study offers some potential pathways that should be tested in future research on how seasonality shapes urban household water insecurity. Our results underscore how researchers cannot assume that access and use of community water systems will necessarily buffer households from seasonality-induced insecurities. Climate change predictions for this region suggest reduced precipitation, higher temperatures and more extreme precipitation events, all of which may further amplify season signals that increase water insecurity experiences and adversely affect human health.

Our study also highlights both the usefulness and applicability of the HWISE Scale and its limits for potentially signalling different adverse health outcomes. We demonstrated that the HWISE Scale was significantly correlated with diarrhoea and perceived stress, but not dengue fever. This is an important finding because it supports the theory that the experience of water insecurity is shaped by multiple dimensions that may operate differently across populations in space and time. ${ }^{67}$ This study demonstrates that although different water insecurity measures may be associated with the same health outcomes, certain dimensions of water insecurity may have stronger relationships with a given health outcome (eg, water worry and PSS; hygiene and diarrhoea). This finding suggests that shorter, construct-specific subscores, rather than the full 12-item HWISE Scale, may be a useful proxy for certain community-level and household-level health risks. The range of health risks that could be detected by shortform, construct-oriented water insecurity subscores-the kinds of scales that can be implemented by lay community members without medical training or via mobile devices-remains a potentially fruitful area of future research.

There are two key limitations of this study. First, we were not able to assess intrahousehold water insecurity, which is emerging as an important research area. We recognise the gendered experience of water insecurity, age differences, complex social relationships and differentiated labour that are involved in domestic water management all shape experiences of insecurity. ${ }^{24} 2568-71$ These issues were beyond the scope of our research design, but remain important research opportunities. Second, our study did not sample the same households in the wet and dry seasons; rather we sampled the same neighbourhood with different households. While our analysis is ecologically sound, we advocate for a longitudinal household study that could capture the specific seasonal changes to better assess linkages between climate, water insecurity and health.

Finally, the HWISE Scale offers an efficient, robust and innovative metric for cross-cultural and unidimensional characteristics of household water insecurity. Household water insecurity experiences in Torreón can be quantitatively compared with experiences elsewhere. Yet, Wutich ${ }^{15}$ notes that water insecurity is often a locally, culturally and geographically unique phenomenon that operates at specific scales. The HWISE Scale does not include items about water quality, which may be an essential driver of water insecurity in some communities. For example, well-known arsenic contamination of public supply likely influences water behaviours and trade-offs to mitigate the risk. Reliance on unprotected sources in Torreón may convey a sense of security as the perception of arsenic exposure risk may be lowered even if other contaminant pathways arise through unprotected sources and requisite water storage. There are other strategies to address these differences, ${ }^{5}$ such as a household water insecurity index, ${ }^{67}$ regional scales ${ }^{69}$ or use of subdomains, ${ }^{72}$ which may be necessary to examine how water insecurity subscores correlate with health and other outcomes.

\section{CONCLUSION}

This case study of lower income communities in Torreón, Mexico, identified water system intermittency, unpredictability and seasonality as structural correlates of household water insecurity. This study also found that an experiential water insecurity scale is associated with two health outcomes, self-reported diarrhoea and perceived stress, but not selfreported dengue fever. Short-form scales may be appropriate screeners of health issues that can be completed by lay workers in settings with limited healthcare resources, particularly in lieu of more expensive microbiological tests that require specialised training and facilities. This work contributes to the growing body of empirical research that has tested explicit metrics of household water insecurity. The HWISE Scale can support further research on how urban water problems, influenced by global urban water development models, intersect with sociospatial inequalities and uneven health burdens experienced by low-income and underemployed populations by offering an efficient means to triangulate these data with other relevant information. ${ }^{73}$ We observed that the experience of water insecurity is directly related to human health, though these types of social measures may only be useful for a limited set of health issues. Our use of the HWISE Scale provides opportunities for replication and regional comparisons, and we encourage future research about the extent to which different short-form water insecurity scales might serve as low-cost proxies of different human health burdens.

Twitter Wendy E Jepson @ProfessorJepson

Contributors WEJ and GC designed the study. WEJ developed the survey and GC, FJUS and JMM contributed to survey design. GC, JMM and FJUS supervised the survey administration and data management. JB, JS and WEJ conducted the 
statistical analysis. WEJ outlined the paper. WEJ, JS and JB drafted the article. All authors reviewed and approved the final draft of the manuscript.

Funding This project was carried out with the support of Texas A\&M University and Consejo Nacional de Ciencia y Tecnologia (CONACyT) (Award number 2017-034).

Competing interests None declared.

Patient consent for publication Not required.

Ethics approval The study received human subject oversight through El Colegio de la Frontera Norte (COLEF) and Universidad de Coahuila-Torreón in Mexico and through the Institutional Review Board of Texas A\&M University in the USA.

Provenance and peer review Not commissioned; externally peer reviewed.

Data availability statement Data are available upon reasonable request. Deidentified participant information may be requested from GC (gcarrillo@srph. tamhsc.edu).

Supplemental material This content has been supplied by the author(s). It has not been vetted by BMJ Publishing Group Limited (BMJ) and may not have been peer-reviewed. Any opinions or recommendations discussed are solely those of the author(s) and are not endorsed by BMJ. BMJ disclaims all liability and responsibility arising from any reliance placed on the content. Where the content includes any translated material, BMJ does not warrant the accuracy and reliability of the translations (including but not limited to local regulations, clinical guidelines, terminology, drug names and drug dosages), and is not responsible for any error and/or omissions arising from translation and adaptation or otherwise.

Open access This is an open access article distributed in accordance with the Creative Commons Attribution Non Commercial (CC BY-NC 4.0) license, which permits others to distribute, remix, adapt, build upon this work non-commercially, and license their derivative works on different terms, provided the original work is properly cited, appropriate credit is given, any changes made indicated, and the use is non-commercial. See: http://creativecommons.org/licenses/by-nc/4.0/.

\section{ORCID iDs}

Wendy E Jepson http://orcid.org/0000-0002-7693-1376

Justin Stoler http://orcid.org/0000-0001-8435-7012

Juha Baek http://orcid.org/0000-0002-4977-9970

\section{REFERENCES}

1 Obeng-Odoom F. Beyond access to water. Dev Pract 2012;22:1135-46.

2 Smiley SL. Complexities of water access in Dar ES Salaam, Tanzania. Appl Geogr 2013;41:132-8.

3 Jepson W. Measuring 'no-win' waterscapes: experience-based scales and classification approaches to assess household water security in colonias on the US-Mexico border. Geoforum 2014;51:107-20.

4 Jepson W, Budds J, Eichelberger L, et al. Advancing human capabilities for water security: a relational approach. Water Secur 2017;1:46-52.

5 Jepson WE, Wutich A, Colllins SM, et al. Progress in household water insecurity metrics: a cross-disciplinary approach. WIREs Water 2017; 4:e1214.

6 Krumdieck NR, Collins SM, Wekesa P, et al. Household water insecurity is associated with a range of negative consequences among pregnant Kenyan women of mixed HIV status. J Water Health 2016;14:1028-31.

7 Workman $\mathrm{CL}$, Ureksoy $\mathrm{H}$. Water insecurity in a syndemic context: understanding the psycho-emotional stress of water insecurity in Lesotho, Africa. Soc Sci Med 2017;179:52-60.

8 Boateng GO, Collins SM, Mbullo P, et al. A novel household water insecurity scale: procedures and psychometric analysis among postpartum women in Western Kenya. PLoS One 2018;13:e0198591.

9 Rosinger AY. Household water insecurity after a historic flood: diarrhea and dehydration in the Bolivian Amazon. Soc Sci Med 2018;197:192-202.

10 Adams EA, Stoler J, Adams Y. Water insecurity and urban poverty in the global South: implications for health and human biology. Am J Hum Biol 2020;32:e23368.

11 Leonard WR. Water \& human biology and new developments for the American Journal of Human Biology. Am J Hum Biol 2020;32:e23389.

12 Piperata BA, Lee S, Mayta Apaza AC, et al. Characterization of the gut microbiota of Nicaraguan children in a water insecure context. Am J Hum Biol 2020;32:e23371.
13 Rosinger AY. Biobehavioral variation in human water needs: how adaptations, early life environments, and the life course affect body water homeostasis. Am J Hum Biol 2020;32:e23338.

14 Rosinger AY, Brewis A. Life and death: toward a human biology of water. Am J Hum Biol 2020;32:e23361.

15 Wutich A. Water insecurity: an agenda for research and call to action for human biology. Am J Hum Biol 2020;32:e23345.

16 Sultana F. Suffering for water, suffering from water: emotional geographies of resource access, control and conflict. Geoforum 2011;42:163-72.

17 Vins $\mathrm{H}$, Bell J, Saha S, et al. The mental health outcomes of drought: a systematic review and causal process diagram. Int $J$ Environ Res Public Health 2015;12:13251-75.

18 Aihara Y, Shrestha S, Sharma J. Household water insecurity, depression and quality of life among postnatal women living in urban Nepal. J Water Health 2016;14:317-24.

19 Bisung E, Elliott SJ. "It makes us really look inferior to outsiders": Coping with psychosocial experiences associated with the lack of access to safe water and sanitation. Can J Public Health 2017;108:442-7.

20 Thomas V, Godfrey S. Understanding water-related emotiona distress for improving water services: a case study from an Ethiopian small town. J Water Sanit Hygiene Develop 2018;8:196-207.

21 Tallman PS. Water insecurity and mental health in the Amazon: economic and ecological drivers of distress. Econ Anthropol 2019;6:304-16.

22 Kangmennaang J, Bisung E, Elliott SJ. 'We are drinking diseases': perception of water insecurity and emotional distress in urban slums in accra, Ghana. Int J Environ Res Public Health 2020;17:890.

23 Wutich A, Ragsdale K. Water insecurity and emotional distress: coping with supply, access, and seasonal variability of water in a Bolivian squatter settlement. Soc Sci Med 2008;67:2116-25.

24 Wutich A. Intrahousehold disparities in women and men's experiences of water insecurity and emotional distress in urban Bolivia. Med Anthropol Q 2009;23:436-54.

25 Stevenson EGJ, Greene LE, Maes KC, et al. Water insecurity in 3 dimensions: An anthropological perspective on water and women's psychosocial distress in Ethiopia. Soc Sci Med 2012;75:392-400.

26 Collins SM, Mbullo Owuor P, Miller JD, et al. 'I know how stressful it is to lack water!' Exploring the lived experiences of household water insecurity among pregnant and postpartum women in western Kenya. Glob Public Health 2019;14:649-62.

27 Hulland KRS, Chase RP, Caruso BA, et al. Sanitation, stress, and life stage: a systematic data collection study among women in Odisha, India. PLoS One 2015; 10:e0141883.

28 O'Reilly K. From toilet insecurity to toilet security: creating safe sanitation for women and girls. Wiley Inter Rev: Water 2016;3:19-24. doi:10.1002/wat2.1122

29 Sclar GD, Penakalapati G, Caruso BA, et al. Exploring the relationship between sanitation and mental and social well-being: a systematic review and qualitative synthesis. Soc Sci Med 2018;217:121-34.

30 Caruso BA, Clasen TF, Hadley C, et al. Understanding and defining sanitation insecurity: women's gendered experiences of urination, defecation and menstruation in rural Odisha, India. BMJ Glob Health 2017;2:e000414.

31 Brewis A, Choudhary N, Wutich A. Low water access as a gendered physiological stressor: blood pressure evidence from Nepal. Am J Hum Biol 2019;31:e23234.

32 Bartram J, Hunter P. Bradley classification of disease transmission routes for water-related hazards. Routledge handbook of water and health. New York: Routledge, 2015: 38-55.

33 Quintero J, Brochero H, Manrique-Saide P, et al. Ecological, biological and social dimensions of dengue vector breeding in five urban settings of Latin America: a multi-country study. BMC Infect Dis 2014;14:38.

34 Lopez-Gatell H, Hernandez-Avila M, Avila JEH. Dengue in Latin America: a persistent and growing public health challenge. Neglected tropical diseases-Latin America and the Caribbean. Springer, 2015: 203-24.

35 Zellweger RM, Cano J, Mangeas M, et al. Socioeconomic and environmental determinants of dengue transmission in an urban setting: an ecological study in Nouméa, new Caledonia. PLoS Negl Trop Dis 2017;11:e0005471.

36 Young SL, Boateng GO, Jamaluddine Z, et al. The household water insecurity experiences (HWISE) scale: development and validation of a household water insecurity measure for low-income and middleincome countries. BMJ Glob Health 2019;4:e001750.

37 Instituto Nacional de Estadistica y Geografia (INEGI). Encuesta intercensal Panorama sociodemográfico de Coahuila de Zaragoza. Aguascalientes, México, 2015. 
38 García-Salazar JA, Mora-Flores JS. Tarifas Y consumo de agua en El sector residencial de la Comarca Lagunera. Región y Sociedad 2008;20:119-32.

39 Cebrián ME, Albores A, Aguilar M, et al. Chronic arsenic poisoning in the North of Mexico. Hum Toxicol 1983;2:121-33.

40 Dorjderem B, Torres-Martínez JA, Mahlknecht J. Intensive long-term pumping in the Principal-Lagunera region aquifer (Mexico) causing heavy impact on groundwater quality. Energy Reports 2020;6:862-7.

41 Comisión Nacional del Agua, El Agua, un Recurso Estratégico Y de Seguridad Nacional. En Donde Estamos. Programa Hidráulico regional 2002- 2006. Región VII Cuencas Centrales del Norte. Mexico: Ministry of the Environment and Natural Resources, 2008.

42 Prüss A, Kay D, Fewtrell L, et al. Estimating the burden of disease from water, sanitation, and hygiene at a global level. Environ Health Perspect 2002;110:537-42.

43 World Health organization. Estimating the burden of diarrheal disease caused by water and sanitation, 2011.

44 Young SL, Collins SM, Boateng GO, et al. Development and validation protocol for an instrument to measure household water insecurity across cultures and ecologies: the household water insecurity experiences (HWISE) scale. BMJ Open 2019;9:e023558.

45 Cohen S, Kamarck T, Mermelstein R. A global measure of perceived stress. J Health Soc Behav 1983;24:385-96.

46 González-Ramírez MT, Rodríguez-Ayán MN, Hernández RL. The perceived stress scale (PSS): normative data and factor structure for a large-scale sample in Mexico. Span J Psychol 2013;16:E47.

47 Remor E. Psychometric properties of a European Spanish version of the perceived stress scale (PSS). Span J Psychol 2006;9:86-93.

48 Remor E. Carrobles JA. Versión Española de la escala de estrés percibido (PSS-14): Estudio psicométrico en Una muestra VIH. Ansiedad y Estrés 2001;7:195-201.

49 Jepson W, Vandewalle E. Household water insecurity in the global North: a study of rural and periurban settlements on the TexasMexico border. The Professional Geographer 2016;68:66-81.

50 Onda K, LoBuglio J, Bartram J. Global access to safe water: accounting for water quality and the resulting impact on mdg progress. Int J Environ Res Public Health 2012;9:880-94.

51 Klingel P. Technical causes and impacts of intermittent water distribution. Water Supply 2012;12:504-12.

52 Galaitsi S, Russell R, Bishara A, et al. Intermittent domestic water supply: a critical review and analysis of causal-consequential pathways. Water 2016;8:274.

53 Kumpel E, Nelson KL. Mechanisms affecting water quality in an intermittent piped water supply. Environ Sci Technol 2014;48:2766-75.

54 Kumpel E, Nelson KL. Intermittent water supply: prevalence, practice, and microbial water quality. Environ Sci Technol 2016;50:542-53.

55 Gottipati PVKSV, Nanduri UV. Equity in water supply in intermittent water distribution networks. Water Environment J 2014;28:509-15.

56 IB-NET Database. International benchmarking network (IBN). Available: https://database.ib-net.org/DefaultNew.aspx
57 Kumpel E, Nelson KL. Comparing microbial water quality in an intermittent and continuous piped water supply. Water Res 2013;47:5176-88.

58 Agathokleous A, Christodoulou S. Vulnerability of urban water distribution networks under intermittent water supply operations. Water Res Manag 2016;30:4731-50.

59 Wutich A, Brewis A, Chavez JBR. Water, worry, and dona paloma: why water security is fundamental to global mental health. In: Kohrt BA, Mendenhall E, eds. Global mental health: anthropological perspectives, 2015: 57-71.

60 Majuru B, Suhrcke M, Hunter P. How do households respond to unreliable water supplies? A systematic review. Int J Environ Res Public Health 2016;13:1222.

61 Abubakar IR. Strategies for coping with inadequate domestic water supply in Abuja, Nigeria. Water Int 2018;43:570-90.

62 Price H, Adams E, Quilliam RS. The difference a day can make: the temporal dynamics of drinking water access and quality in urban slums. Sci Total Environ 2019;671:818-26.

63 Lee GO, Whitney HJ, Blum AG, et al. Household coping strategies associated with unreliable water supplies and diarrhea in Ecuador, an upper-middle-income country. Water Res 2020;170:115269.

64 Stoler J, Pearson AL, Staddon C, et al. Cash water expenditures are associated with household water insecurity, food insecurity, and perceived stress in study sites across 20 low- and middle-income countries. Sci Total Environ 2020;716:135881.

65 Wutich A, Rosinger AY, Stoler J, et al. Measuring human water needs. Am J Hum Biol 2020;32:e23350.

66 Miller JD, Vonk J, Staddon C, et al. Is household water insecurity a link between water governance and well-being? A multi-site analysis. $J$ Water Sanitation Hygiene Develop 2020;10:320-34.

67 Tomaz P, Jepson W, Santos JdeO. Urban household water insecurity from the margins: perspectives from northeast Brazil. The Professional Geographer 2020;72:481-98.

68 Kher J, Aggarwal S, Punhani G. Vulnerability of poor urban women to climate-linked water insecurities at the household level: a case study of slums in Delhi. Indian J Gend Stud 2015;22:15-40.

69 Tsai AC, Kakuhikire B, Mushavi R, et al. Population-Based study of intra-household gender differences in water insecurity: reliability and validity of a survey instrument for use in rural Uganda. $J$ Water Health 2016;14:280-92.

70 Harris L, Kleiber D, Goldin J, et al. Intersections of gender and water: comparative approaches to everyday gendered negotiations of water access in underserved areas of Accra, Ghana and Cape town, South Africa. J Gend Stud 2017;26:561-82.

71 Cooper-Vince CE, Arachy $\mathrm{H}$, Kakuhikire B, et al. Water insecurity and gendered risk for depression in rural Uganda: a hotspot analysis. BMC Public Health 2018;18.

72 Brewis A, Workman C, Wutich A, et al. Household water insecurity is strongly associated with food insecurity: evidence from 27 sites in low- and middle-income countries. Am J Hum Biol 2020;32:e23309.

73 Obeng-Odoom F. III health unleashed? cities and municipal services in Ghana. Rev Afr Polit Econ 2011;38:43-60. 